\title{
Isolasi dan Ekstraksi Kelompok Senyawa Flavonoid dari Ekstrak Daun Cocor Bebek (Kalanchoe pinnata)
}

\author{
Atikah Halimah Putri*, Ria Siti Putriyana, Novia Silviani
}

Teknik Kimia, Politeknik Negeri Bandung, Bandung 40012

INFO ARTIKEL

\begin{tabular}{l}
\hline Diterima 17 Juli 2019 \\
Disetujui 1 Agustus 2019 \\
\hline Key word: \\
Cocor Bebek (Kalanchoe \\
pinnata), \\
Extraction, \\
Flavonoids, \\
Thin layer chromatography \\
\hline Kata kunci: \\
Cocor bebek (Kalanchoe \\
pinnata), \\
Ekstraksi, \\
Flavonoid, \\
Kromatografi lapis \\
tipis \\
\end{tabular}

*e-mail: atikahhp16@gmail.com

*Telp: 08179294177

\begin{abstract}
A BSTRACT
Cocor bebek contains secondary metabolites which are useful in the field of pharmacology. This experiment aims to isolate flavonoid compounds which are secondary metabolites in cocor bebek. The extraction method uses maceration with methanol solvents, followed by partitions using ethyl acetate solvents. Identification of flavanoid group compounds was analyzed qualitative testing using FTIR and Thin Layer Chromatography (TLC) with the mobile phase of ethyl acetate: n-hexane with a ratio of $8: 2,7: 3,5: 5,3: 7$, and $2: 8$. The experimental results obtained from 600 grams of fresh cocor bebek leaves producing 3 gram of flavonoid extract. The qualitative test gave positive results for the TLC method the presence of flavonoids in the leaves of cocor bebek on spot yellow. While the levels of flavonoids in the extract of cocor bebek are obtained $4.20 \mathrm{ppm}$.
\end{abstract}

\section{A B STRAK}

Daun Cocor bebek (Kalanchoe pinnata) yang mengandung senyawa metabolit sekunder yang bermanfaat dalam bidang farmakologi. Percobaan ini bertujuan untuk mengisolasi senyawa golongan flavonoid pada tanaman cocor bebek. Metode ekstraksi menggunakan maserasi dengan pelarut metanol yang dilanjutkan dengan partisi menggunakan pelarut etil asetat. Identifikasi senyawa golongan flavanoid dianalisis secara kualitatif menggunakan FTIR dan Kromatografi Lapis Tipis (KLT) dengan fasa gerak etil asetat : n-heksan dengan perbandingan 8:2, 7:3, 5:5, 3:7, dan 2:8. Hasil percobaan diperoleh dalam 600 gram daun cocor bebek segar menghasilkan ekstrak flavonoid 3 gram. Uji kualitatif menggunakan metode KLT memberikkan hasil positif adanya senyawa golongan flavonoid dalam daun cocor bebek yang ditandai bercak berwarna kuning kehijauan. Sementara kadar flavonoid di dalam ekstrak cocor bebek diperoleh 4,20 ppm.

\section{Pendahuluan}

Indonesia merupakan salah satu negara yang terkenal akan keanekaragaman hayati, khususnya tanaman yang dapat digunakan sebgai obat sejak zaman nenek moyang kita. Dari sekitar 30.000 species tanaman yang ada di Indonesia, 7.000 species merupakan tanaman obat dan 4.500 species diantaranya berasal dari pulau Jawa [1]. Di dalam tanaman tersebut terdapat senyawa organik bahan alam sangat penting peranannya dalam bidang farmakologi. Studi bahan alam dalam bidang kimia dapat beraspek luas antara lain suatu penelitian terhadap struktur dan biosintesis, isolasi dan identifikasi senyawa-senyawa berkhasiat atau berguna. Senyawa bahan alam yang telah banyak dimanfaatkan sebagai obat merupakan senyawa metabolit sekunder. Salah satu senyawa metabolit sekunder yang tersebar merata dalam dunia tumbuh-tumbuhan dan ditemukan pada hampir semua bagian tumbuhan termasuk daun, akar, kayu, kulit, tepung sari, nectar, bunga, buah dan biji adalah senyawa Flavonoid.

Tanaman cocor bebek (Kalanchoe pinnata) merupakan tanaman yang mudah 
untuk dibudidayakan di Indonesia. Tanaman cocor bebek tidak hanya digunakan sebagai tanaman hias, tetapi juga dapat digunakan sebgai tanaman obat. Kandungan kimia dalam daun cocor bebek antara lain senyawa steroid, alkaloid, flavonoid, saponin, dan tanin [2]. Dalam percobaan ini bertujuan untuk mengidentifikasi senyawa bahan alam golongan flavonoid yang terdapat di dalam daun cocor bebek. Untuk mendapatkan senyawa metabolit sekunder flavonoid dari cocor bebek maka dilakukan proses isolasi sehingga dihasilkan senyawa tunggal (murni).

Flavanoid mempunyai kerangka dasar karbon yang terdiri dari 15 atom karbon, dimana dua cincin benzena $\left(\mathrm{C}_{6}\right)$ terikat pada suatu rantai propana ( $\left.\mathrm{C}_{3}\right)$ sehingga membentuk suatu susunan $\mathrm{C}_{6}-\mathrm{C}_{3}-\mathrm{C}_{6}$. Senyawa flavanoid merupakan suatu kelompok senyawa fenol yang terbesar yang ditemukan di alam. Senyawasenyawa ini merupakan zat warna merah, ungu, dan biru serta sebagai zat warna kuning yang ditemukan dalam tumbuh-tumbuhan. Menurut Koosha (2016) flavonoid terdiri dari subkelas utama yaitu flavonol, flavon, flavanon, flavan-3ol, flavanol [3].<smiles>O=c1cc(-c2ccccc2)oc2ccccc12</smiles>

\section{Gambar 1. Struktur Dasar Flavonoid}

Isolasi flavonoid akan difokuskan pada ekstrak metanol. Proses ekstraksi dilakukukan dengan metode maserasi. Senyawa flavonoid pada umumnya mudah larut dalam air, terutama bentuk glikosidanya. Senyawa tersebut dapat diekstrak menggunakan pelarut air. Senyawa yang sedikit larut dalam air bersifat semi polar dapat diekstraksi dengan pelarut metanol, aseton, dan etanol ditinjau dari karakteristik kepolaran dari tanaman cocor bebek [2].

Uji kualitatif dilakukan dengan metode kromatografi lapis tipis dan spektrofotometer IR. Sedangkan untuk uji kuantitatif dapat dilakukan menggunakan spektrofotometer UVVis yaitu dengan mengukur nilai absorbansi karena flavonoid mengandung sistem aromatis yang terkonjugasi dan dapat menunjukkan pita serapan kuat pada daerah UV-Vis [4]. Absorbansi sebagai analisa kuantitatif dilakukan berdasarkan Hukum Lambert-Beer. Menurut Dirjen POM (2014) range nilai absorbansi yang baik yaitu berkisar antara 0,20,8 di daerah ultraviolet atau cahaya tampak [5]. Berdasarkan Hukum Lambert-Beer, rumus yang digunakan untuk menghitung banyaknya cahaya yang hamburkan:

$$
A=a \times b \times c
$$

Dengan:

$$
\begin{aligned}
& \mathrm{A}=\text { absorbansi (serapan) } \\
& \mathrm{a}=\text { Absortifitas molar }\left(\mathrm{M}^{-1} \mathrm{~cm}^{-1}\right) \\
& \mathrm{b}=\text { tebal kuvet }(\mathrm{cm}) \\
& \mathrm{c}=\operatorname{konsentrasi}(\mathrm{M})
\end{aligned}
$$

\section{Bahan dan Metode}

Tahap Preparasi

Timbang daun cocor bebek kemudian cuci hinggga bersih. Daun cocor bebek dipotong kecil-kecil dan dihaluskan.

\section{Tahap Ekstraksi Daun Cocor bebek (Kalanchoe pinnata)}

Sebanyak 600 gram daun cocor bebek halus diekstraksi menggunakan 1,5 L pelarut metanol. Ekstraksi dilakukan dengan cara maserasi dingin selama $3 \times 24$ jam.

\section{Pemekatan atau Pengkisatan}

Proses ini dilakukan dengan pemanasan menggunakan wather bath. Suhu pemanasan berkisar $70^{\circ} \mathrm{C}$ agar tidak merusak ekstrak yang dihasilkan. Proses pemekatan dilakukan hingga dipastikan pelarut metanol telah menguap sempurna.

\section{Partisi}

Metode yang digunakan adalah partisi cair cair. Jika suatu cairan ditambahkan ke dalam ekstrak yang telah dilarutkan dalam cairan lain yang tidak dapat bercampur dengan yang pertama, akan terbentuk dua lapisan. Satu komponen dari campuran akan memiliki kelarutan dalam kedua lapisan tersebut (biasanya disebut fasa) dan setelah beberapa waktu dicapai kesetimbangan konsentrasi 
dalam kedua lapisan. Waktu yang diperlukan untuk tercapainya kesetimbangan biasanya dipersingkat oleh pencampuran keduanya dalam corong pisah [6].

\section{Pengujian Hasil Ekstraksi Setelah Pemekatan} Uji Kualitatif Kromatografi Lapis Tipis

Fase diam berupa pelat silika gel $\mathrm{GF}_{254}$ dan fase gerak berupa kombinasi pelarut etil asetat : $n$-heksan (8:2), (7:3), (5:5), (3:7), dan (2:8). Pelat KLT dimasukkan ke dalam bejana kromatografi yang sebelumnya telah dijenuhkan dengan fase gerak. Pola kromatogram diamati setelah disemprot dengan reagen $\mathrm{AlCl}_{3}$ dan amati warna penampak bercak (noda).

\section{Uji Kualitatif Menggunakan Spektrofotometer Infra} Red (FTIR)

Analisis gugus fungsi suatu sampel dilakukan dengan membandingkan pita absorbsi yang terbentuk pada spektrum infra merah menggunakan tabel korelasi dan menggunakan spektrum senyawa pembanding (yang sudah diketahui).

Uji Kuantitatif Menggunakan Spektrofotometer Visibel Metode $\mathrm{AlCl}_{3}$

Penentuan Panjang Gelombang Maksimum ( $\chi$ Maks) Kuersetin dilakukan melalui running larutan kuersetin pada range panjang gelombang UV-Vis $400-450 \mathrm{~nm}$. Standar kuersetin yang digunakan adalah 2; 4; 6; 8; 10; dan 12 ppm. Konsentrasi larutan standar kuersetin dan sampel dipipet $1 \mathrm{~mL}$ dan ditambahkan $1 \mathrm{~mL} \mathrm{AlCl} 32 \%$ dan $1 \mathrm{~mL}$ kalium asetat $120 \mathrm{mM}$. Sampel diinkubasi selama 30 menit pada suhu kamar dalam wadah tertutup [4].

Berdasarkan pengukuran absorbansi, konsentrasi flavonoid dibaca dalam $(\mu \mathrm{g} / \mathrm{mL})$ garis kalibrasi, kemudian kandungan flavonoid dalam ekstrak dinyatakan dalam ekuivalen kuersetin (mgQE/g ekstrak).

\section{Hasil dan Pembahasan}

\section{Preparasi Sampel}

Pada preparasi sampel dimulai dengan penghalusan, penghalusan daun cocor bebek bertujuan untuk memaksimalkan pembebasan senyawa aktif yang terkandung didalamnya karena dinding sel cocor bebek akan rusak sehingga zat aktif terekstraksi dalam pelarut yang digunakan. Pelarut yang digunakan adalah metanol karena mempunyai sifat like dissolve like yaitu suatu zat akan terlarut dengan baik pada pelarut yang memiliki polaritas yang sama.. Dalam metanol terdapat gugus hidroksil pada strukturnya yang membuat metanol mampu menarik semua komponen polar, sedangkan adanya gugus metil membuat metanol mampu menarik semua komponen non-polar yang terkandung dalam daun $K$. Pinnata [7].

\section{Metode Ekstraksi}

Maserasi adalah proses pengekstrakan simplisia dengan menggunakan pelarut dengan beberapa kali pengadukan pada temperatur ruangan. Maserasi dilakukan menggunakan pelarut metanol selama 3×24 jam. Diperoleh hasil ekstraksi daun cocor bebek sebagai berikut:

Tabel 1. Hasil Ekstraksi Daun Cocor bebek (Kalanchoe pinnata)

\begin{tabular}{ccl}
\hline Hari Ke & $\begin{array}{c}\text { Jumlah } \\
\text { Penambahan } \\
\text { Metanol }(\mathrm{mL})\end{array}$ & $\begin{array}{c}\text { Ekstrak cocor bebek } \\
\text { (Kalanchoe pinnata })\end{array}$ \\
\hline 1 & 600 & $\begin{array}{l}\text { Warna larutan hijau } \\
\text { pekat dan tidak } \\
\text { terdapat kekeruhan }\end{array}$ \\
\hline 2 & 600 & Warna larutan hijau \\
\hline 3 & 490 & Warna larutan hijau \\
\hline 4 & 600 & $\begin{array}{l}\text { Warna larutan hijau } \\
\text { muda }\end{array}$ \\
\hline 5 & 500 & $\begin{array}{l}\text { Warna larutan hijau } \\
\text { muda }\end{array}$ \\
\hline
\end{tabular}

Maserasi 24 jam pertama menghasilkan ekstrak berwarna hijau pekat yang menandakan bahwa ekstrak cocor bebek masih banyak mengandung air sehingga kemungkinan air ikut terekstraksi bersama zat aktif lainnya. Dilakukan maserasi berikutnya pada rafinat cocor bebek. Ektrak cocor bebek dalam metanol yang sudah terkumpul pada hari petama mengalami perubahan warna menjadi kuning kehijauan dan terdapat gumpalan bertekstur seperti karamel berwarna cokelat. Zat ini kemungkinan adalah getah daun yang terakumulasi pada ekstrak setelah didiamkan selama berjam-jam yang kemudian dapat dihilangkan dengan cara disaring. Maserasi dilakukan sampai diperkirakan zat aktif dalam daun cocor bebek sudah terekstraksi semua 
yang ditandai dengan warna larutan hijau muda.

\section{Pemekatan Menggunakan Metode Penguapan}

Hasil ekstrak metanol yang diperoleh diuapkan pada suhu penguapan $\pm 70^{\circ} \mathrm{C}$ sehingga suhu tersebut cukup baik untuk penguapan cocor bebek. Suhu yang terlalu tinggi akan menyebabkan senyawa yang terkandung mengalami dekomposisi, sehingga hal tersebut dihindari pada proses ini. Proses pemekatan menghasilkan ekstrak cocor bebek yang lebih kental dan warnanya semakin pekat (hijau kehitaman).

Partisi

Metode partisi yang digunakan adalah ekstraksi cair-cair berdasarkan perbedaan kepolaran larutan. Pelarut yang digunakan adalah etil asetat. Partisi dilakukan sebanyak tiga kali hingga diperoleh ekstrak yang mempunyai warna yang lebih pudar dari warna sebelumnya. Proses ekstraksi ini menghasilkan dua fasa, dimana lapisan atas adalah fraksi etil asetat dan lapisan bawah adalah fraksi air. Fraksi etil asetat inilah yang mengandung senyawa flavonoid yang bersifat polar. Kemudian fraksi etil asetat dilakukan pemekatan hingga menghasilkan ekstrak etil asetat sebanyak 3 gram. Pada proses pemekatan fraksi etil asetat ini, ekstrak berbentuk pasta dengan warna menjadi lebih pekat dari sebelumnya (hijau kehitaman).

Uji Kualitatif Flavonoid Menggunakan Metode Kromatografi Lapis Tipis

Analisis dengan menggunakan KLT merupakan pemisahan komponen kimia berdasarkan prinsip adsorbsi dan partisi yang ditentukan oleh fase diam (adsorben) dan fase gerak (pelarut).
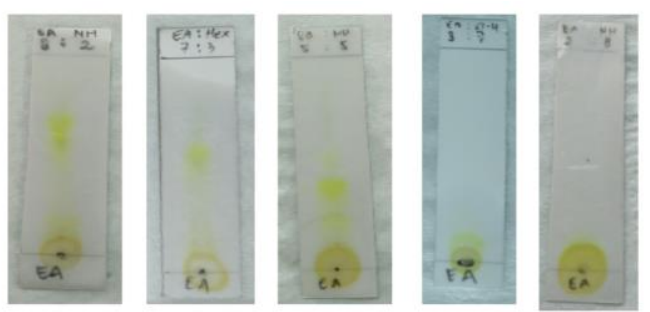

Gambar 2. Hasil Uji Flavonoid Menggunakan KLT
Hasil percobaan diperoleh bentuk bercak yang dari eluen dengan berbagai perbandingan memberikan hasil uji positif terkandung flavonoid dalam esktrak cocor bebek (Kalanchoe pinnata) yang ditandai dengan warna hijau yang semakin terlihat ketika disemprotkan reagen $\mathrm{AlCl}_{3}$. Perbandingan eluen yang digunakan etil asetat: $n$-heksan (8:2), (7:3), (5:5), (3:7), dan (2:8) memberikan hasil pemisahan yang berbedabeda. Hasil terbaik diperoleh dengan perbandingan eluen etil asetat: $n$-heksan (8:2). Penggunaan reagen $\mathrm{AlCl}_{3}$ karena struktur kimia $\mathrm{AlCl}_{3}$ dapat berikatan dengan senyawa flavonoid sehingga terjadi pendaran yang akan memunculkan warna yang khas dari flavonoid yaitu warna hijau terang.

\section{Uji Kualitatif Flavonoid Menggunakan} Spektrofotometri Inframerah

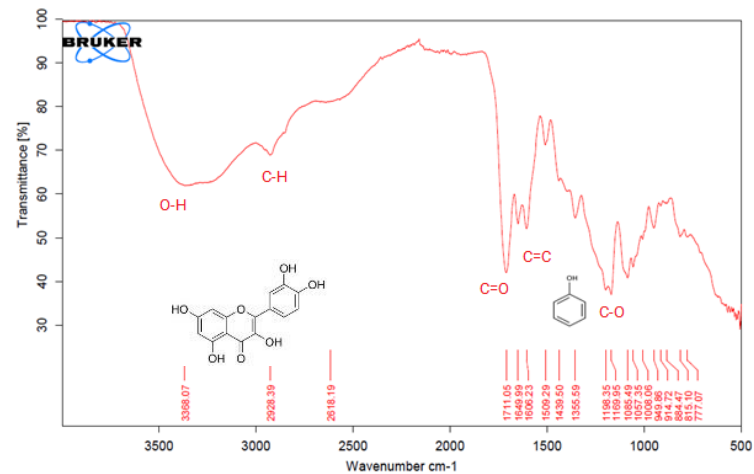

Gambar 3. Spektrum Inframerah dari senyawa Isolat

Isolat diuji menggunakan spektrofotometer inframerah untuk mengetahui gugus senyawa golongan kelompok flavonoid. Spektrum yang didapat ditampilkan pada gambar. $X$ dan karakteristik dari posisi puncak dijelaskan pada tabel. X. Karakteristik spektrum IR dari isolat dibandingkan dengan spektrum senyawa Quercetin dari literatur [8].

Berdasarkan analisis spektrum inframerah pada gambar 3, menunjukan adanya beberapa gugus fungsi. Hasil analisis isolat ini yaitu adanya serapan melebar dengan intensitas lemah pada daerah bilangan gelombang 3368.07 $\mathrm{cm}^{-1}$ yang diduga adalah serapan uluran dari gugus $\mathrm{O}-\mathrm{H}$ pada fenol. Serapan uluran $\mathrm{C}-\mathrm{H}$ alifatik yang tajam dan lemah muncul pada daerah bilangan gelombang $2928.39 \mathrm{~cm}^{-1}$. 
Adanya gugus karbonil $(\mathrm{C}=\mathrm{O})$ sebagai ciri umum senyawa golongan flavonoid diindikasikan oleh adanya serapan pada daerah bilangan gelombang $1711.05 \mathrm{~cm}-1$ [9]. Serapan uluran $\mathrm{C}-\mathrm{-} \mathrm{C}, \mathrm{C}=\mathrm{O}$, dan $\mathrm{C}=\mathrm{C}$ aromatik muncul pada daerah bilangan gelombang $1649.99 \mathrm{~cm}^{-1}$, $1509.29 \mathrm{~cm}^{-1}, 1439.50 \mathrm{~cm}^{-1}$.

Tabel 2. Interpretasi Spektrum Inframerah dari Isolat

\begin{tabular}{ll}
\hline Posisi Puncak & \multicolumn{1}{c}{$\begin{array}{c}\text { Kemungkinan } \\
\text { Gugus Fungsi }\end{array}$} \\
\hline 3368.07 & Uluran O-H pada \\
& fenol \\
& Uluran C-H \\
2928.39 & Uluran C=O \\
1711.05 & Uluran C---C dari \\
1649.99 & cincin aromatik \\
& Uluran C=O \\
& aromatic \\
& Uluran C=C \\
& aromatik \\
1509.29 & $\begin{array}{l}\text { Pembengkokan O-H } \\
\text { pada fenol }\end{array}$ \\
& Uluran C-O pada \\
1439.50 & fenol \\
& \\
& Pembengkokan C-H \\
1355.59 & pada hidrokarbon \\
& aromatic \\
$1008.06,1057.35$, &
\end{tabular}

$949.86,815.10,777.07$

Vibrasi pembengkokan $\mathrm{O}-\mathrm{H}$ dari fenol diamati pada $1355.59 \mathrm{~cm}^{-1}$. Kemudian vibrasi ulur C-O dalam senyawa fenol menghasilkan pita kuat di daerah $1260-1000 \mathrm{~cm}^{-1}$ dan pada isolat ini serapan C-O muncul pada daerah bilangan gelombang $1008.06 \mathrm{~cm}^{-1}, 1057.35 \mathrm{~cm}^{-1}$, $1085.49 \mathrm{~cm}^{-1}, 1169.95 \mathrm{~cm}^{-1}, 1198.35 \mathrm{~cm}^{-1}$ [10]. Sementara itu serapan pada bilangan gelombang adanya gugus $\mathrm{C}-\mathrm{H}$ aromatik menghasilkan pita di daerah $1000-650 \mathrm{~cm}^{-1}$ dan pada isolat ini serapan $\mathrm{C}-\mathrm{H}$ aromatik muncul pada daerah bilangan gelombang $949.86 \mathrm{~cm}^{-1}$, $815.10 \mathrm{~cm}^{-1}, 777.07 \mathrm{~cm}^{-1}$ [10]. Adanya gugus fungsi $\mathrm{OH}, \mathrm{CH}$ alifatik, $\mathrm{C}=\mathrm{O}, \mathrm{C}=\mathrm{C}$ aromatik dan $\mathrm{C}-\mathrm{O}$ mengindikasikan isolat ini suatu senyawa flavonoid [11].

\section{Uji Kuantitatif Kadar Flavonoid}

Prinsip penetapan kadar flavonoid metode $\mathrm{AlCl}_{3}$ adalah terjadinya pembentukan kompleks antara $\mathrm{AlCl}_{3}$ dengan gugus keto pada atom C-4 dan gugus hidroksi pada atom C-3 atau C-5 yang bertetangga dari golongan flavon dan flavonol. Senyawa yang digunakan sebagai standar pada penetapan kadar flavonoid ini adalah quersetin, karena quersetin merupakan flavonoid golongan flavonol yang memiliki gugus karbonil pada atom C-4 dan juga gugus hidroksil pada atom C-3 dan C-5 yang bertetangga.

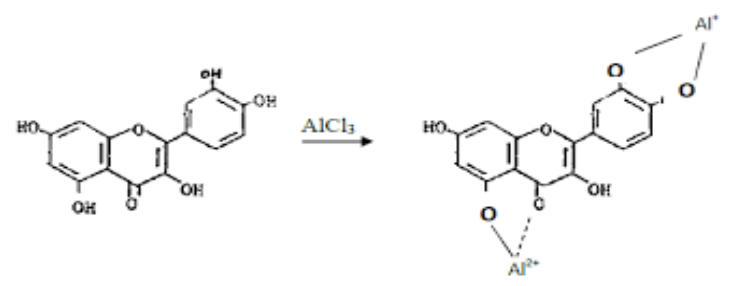

Gambar 4. Pembentukan senyawa kompleks quersetin-alumunium klorida

Berikut tabel hasil Absorbansi dari deret larutan standar Kuarsetin dan Kurva kalibrasi dari deret larutan standar:

Tabel 3. Hasil absorbansi dari deret larutan standar kuarsetin

\begin{tabular}{|c|c|}
\hline Konsentrasi (ppm) & Absorbansi \\
\hline 2 & 0,049 \\
\hline 4 & 0,1321 \\
\hline 6 & 0,1737 \\
\hline 8 & 0,205 \\
\hline 10 & 0,252 \\
\hline 12 & 0,3289 \\
\hline
\end{tabular}

Dalam percobaan dilakukan pada pada panjang gelombang maksimum $437,55 \mathrm{~nm}$, dan diperoleh persamaan garis $\mathrm{y}=0,0512 \mathrm{x}+0,0111$ dengan $R^{2}=0,9773$. Dari kurva tersebut, dilihat bahwa absorbansi berbanding lurus dengan konsentrasi. Hal ini sesuai dengan Hukum Lambert-Beer $\mathrm{A}=\mathrm{a} \times \mathrm{b} \times \mathrm{C}$. Absorbansi sampel menunjukan 0,2257, sehingga kadar flavonoid berdasarkan pengukuran spektrfotometer visibel dalam sampel 4,20 ppm. 


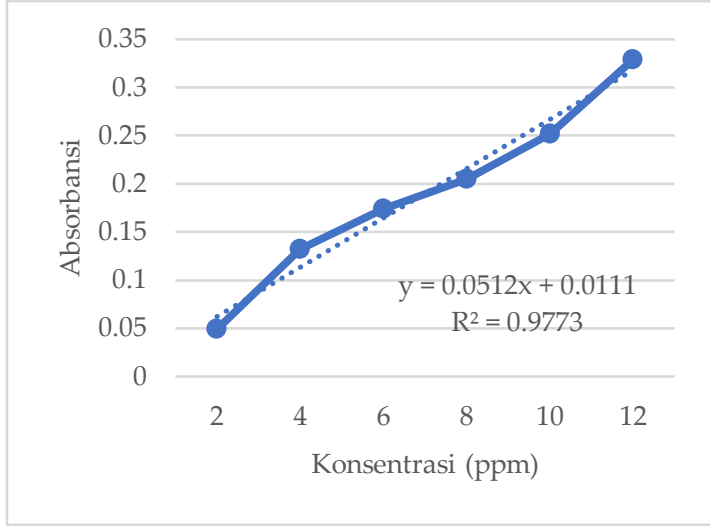

Gambar 5. Kurva Kalibrasi Larutan Standar Quarsetin

\section{Kesimpulan}

Berdasarkan penelitian yang kami dilakukan, daun cocor bebek (Kalanchoe pinnata) segar sebanyak 600 gram menghasilkan ekstrak etil asetat sebanyak 3 gram.Hasil uji positif pada identifikasi flavanoid dalam ekstrak cocor bebek (Kalanchoe pinnata) yang dilakukan secara kualitatif dengan FTIR dan Kromatografi Lapis Tipis (KLT) menggunakan eluen etil asetat: $n$ heksan.Kadar Flavonoid dalam daun cocor bebek 4,20 ppm.

\section{Daftar Pustaka}

1. DirektoratPengawasanObatTradisional, Parameter standar umum ekstrak tumbuhan obat. Departemen Kesehatan, Jakarta: 2000.

2. Saputra, T. R.; Ngatin, A.; Sarungu, Y. T., Penggunaan metode ekstraksi maserasi dan partisi pada tumbuhan cocor bebek (kalanchoe pinnata) dengan kepolaran berbeda. Fullerene Journal of Chemistry 2018, 3, (1), 5-8.

3. Koosha, S.; Alshawsh, M. A.; Looi, C. Y.; Seyedan, A.; Mohamed, Z., An association map on the effect of flavonoids on the signaling pathways in colorectal cancer. International journal of medical sciences 2016, 13, (5), 374.

4. Salmia, S. Analisis Kadar Flavonoid Total Ekstrak Kulit Batang Kedondong Bangkok (Spondias dulcis) dengan Metode Spektrofotometri UV-Vis. Universitas Islam Negeri Alauddin Makassar, 2016.

5. DitjenPOM, Farmakope Indonesia. Departemen Kesehatan RI: Jakarta, 1987.

6. Tobo, F., Buku Pegangan Laboratorium
Fitokimia I. Universitas Hasanuddin, Makassar 2001.

7. Saputra, T. R.; Ngatin, A., Ekstraksi Daun Cocor Bebek Menggunakan Berbagai Pelarut Organik Sebagai Inhibitor Korosi Pada Lingkungan Asam Klorida. Fullerene Journal of Chemistry 2019, 4, (1), 21-27.

8. Sambandam, B.; Thiyagarajan, D.; Ayyaswamy, A.; Raman, P.; Kulasekaran, J.; Venkatasamy, H., Extraction and isolation of flavonoid quercetin from the leaves of Trigonella foenum-graecum and their anti-oxidant activity. Int $J$ Pharm Pharm Sci 2016, 8, (6), 120-4.

9. Sukadana, I. M., Aktivitas antibakteri senyawa flavonoid Dari kulit akar awarawar (Ficus septica Burm F). Jurnal Kimia (Journal of Chemistry) 2010.

10. Silverstein, R. M.; Webster, F. X.; Kiemle, D. J.; Bryce, D. L., Spectrometric identification of organic compounds. John wiley \& sons: 2014.

11. Markham, K. R., Cara mengidentifikasi Flavonoid. ITB: Bandung, Indonesia, 1988. 